\title{
Note
}

\section{Effects of Counter-ion Form of a Cation-exchange Resin and Ethanol Content of Eluent on the Distribution Coefficients of Galactose, Tagatose, and Talose onto the Resin}

\author{
Ango Tamura, Yuki Sha and Shuji Adachi ${ }^{*}$ \\ Division of Food Science and Biotechnology, Graduate School of Agriculture, Kyoto University, Sakyo-ku, Kyoto 606-850, \\ Japan
}

Received October 20, 2015 ; Accepted December 9, 2015

Optimum conditions for chromatographic separation, at $30^{\circ} \mathrm{C}$, of galactose, tagatose, and talose were determined by investigation of the effects of the counter-ion form of cation-exchange resin and the ethanol content of eluent on the distribution coefficients of the monosaccharides onto the resin. Resin in the $\mathrm{K}^{+}$form with a divinylbenzene content of $8 \%$ was found to be most suitable for the separation. The distribution coefficients of all the solutes on the resin were increased as the ethanol content of eluent increased.

Keywords: cation-exchange resin, distribution coefficient, tagatose

\section{Introduction}

Rare sugars are saccharides that occur in only small amounts in nature, and some of them have attracted attention due to their physiological functionality. Xylitol is one such rare sugar, which has an anticaries effect (Söderling et al., 1989) and is contained in gum as a sweetener. D-Psicose, which is an epimer of D-fructose at the $\mathrm{C}-3$ position, is very low in calories and has a beneficial effect on insulin resistance (Matsuo et al., 2002; Hossain et al., 2012). D-Allose, which is an epimer of D-glucose at the C-3 position, has demonstrated preventative effects in ischemia reperfusion injury and hyperpiesia. However, rare sugars are generally very expensive. The high cost restricts investigation of their physiological and textural functionalities. Because of this, the development of effective mass production processes for rare sugars is desired to promote these investigations and achieve industrialization of the production process.

Enzymatic methods for producing rare sugars (Takeshita et al., 2000; Granström et al., 2004; Morimoto et al., 2006) have been reported, in addition to a method using anion exchange (Takamine et al., 2009). We reported that isomerization of the common sugar
D-galactose to D-tagatose and D-talose, which are rare sugars, was promoted in subcritical aqueous ethanol (Gao et al., 2015). An enzymatic method has also been developed for the production of D-tagatose (Kim et al., 2003). Isomerization in a subcritical fluid would be expected to be more effective than in conventional methods because of a higher reaction rate at higher temperature. D-Tagatose, which is a C-4 epimer of fructose, shows promise as replacement for sucrose and as a therapeutic agent against type 2 diabetes and obesity (Levin et al., 1995; Lu et al., 2008).

Because isomerization of D-galactose produces a mixture of unreacted substrate and the products D-tagatose and D-talose, a separation process is required to obtain the desired product, D-tagatose. Ligand-exchange chromatography using cationexchange resin has been commonly used in saccharide separation due to the difference in complex formation or affinity between the counter-ion of the resin and the saccharides (Goulding, 1975; Caruel et al., 1991; Stefansson and Westerlund, 1996). Because water is used as an eluent, the chromatographic separation of saccharides is suitable for industrial purposes. The type of counterion and the divinylbenzene (DVB) content of the resin affect the 
separation efficiency for cation-exchange resins made from styrene cross-linked with DVB. The eluent composition also affects the separation efficiency. We reported that the ethanol content of the eluent affected the distribution coefficients of glucose, maltose and maltotriose onto the cation-exchange resin in the sodium-ion form when a mixture of ethanol and water was used as the eluent, and that the coefficients were larger at higher ethanol content in the eluent (Adachi and Matsuno, 1997).

In this study, we investigated the effects of the degree of crosslinkage of the cation-exchange resin, the counter-ion form of the resin, and the ethanol content of eluent on the apparent distribution coefficients of D-galactose, D-tagatose, and D-talose, because D-tagatose is produced from their mixture in our isomerization method using subcritical fluid.

\section{Materials and Methods}

Materials Cation-exchange resins with sulphonate groups and DVB contents of $6 \%$ and $8 \%$, which were designated UBK530 and UBK550, were used in $\mathrm{Na}^{+}$form. They were supplied by Mitsubishi Chemical Corp., Tokyo, and the diameter of both the resins was $220 \mu \mathrm{m}$. D-Galactose, D-tagatose, and D-talose were purchased from Wako Pure Chemical Industries, Osaka, Japan. In this study, only D-enantiomers were used, and therefore, the prefix, D-, of all saccharides is omitted hereafter. Dextran T-110 with an average molecular mass of $c a .1 .1 \times 10^{5}$, was purchased from Extrasynthase, Lyon, France, and used to estimate the bed voidage. Other chemicals were purchased from Wako or Nacalai Tesque, Kyoto, Japan.

Properties of the cation-exchange resin The resins had been conditioned into the sodium form by the supplier. The resin was converted into the hydrogen-ion form according to standard procedures. The resin was packed into a cylindrical glass column at a bed height. The resin was converted into the lithium-ion form by applying a sufficient amount of $1.0 \mathrm{~mol} / \mathrm{L}$ lithium chloride to the bed, and successive washing with distilled water. The bed height was recorded. The ion-form of the resin was converted to the sodium-, potassium-, calcium- and magnesium-ion form in this order by supplying $1.0 \mathrm{~mol} / \mathrm{L}$ sodium, $1.0 \mathrm{~mol} / \mathrm{L}$ potassium, $0.5 \mathrm{~mol} / \mathrm{L}$ calcium and $0.5 \mathrm{~mol} / \mathrm{L}$ magnesium chloride, respectively, and the bed height for the resin in the respective ion form was recorded.

The apparent density of each resin, $\rho_{\text {app }}$, was pycnometrically determined at $30^{\circ} \mathrm{C}$.

Wet resin, $w_{\mathrm{w}}$, was dried to a constant weight, $w_{\mathrm{d}}$, in an air oven (DN400, Yamato Scientific, Tokyo, Japan) at $135^{\circ} \mathrm{C}$ for $5 \mathrm{~h}$. The porosity of the resin, $\varepsilon_{\mathrm{p}}$, was estimated by the following equation (Eq. (1)):

$$
\varepsilon_{\mathrm{p}}=\frac{\left(w_{\mathrm{w}}-w_{\mathrm{d}}\right) / \rho_{\mathrm{w}}}{w_{\mathrm{w}} / \rho_{\text {app }}}
$$

where $\rho_{\mathrm{w}}$ is the density of water.

Bed shrinkage with ethanol The cation-exchange resin in the $\mathrm{K}^{+}$form and with a DVB content of $8 \%$ was suspended in water and packed in the cylindrical column to give a bed height of $c a$. $25 \mathrm{~cm}$, which was precisely measured. Then a $10 \%(\mathrm{v} / \mathrm{v})$ ethanol solution was continuously fed into the bed until the bed height reached a constant value. After the bed height was recorded, ethanol solutions of 20,30 , and $40 \%$ (v/v) were sequentially fed into the bed and the bed height was recorded.

Distribution coefficient After conversion to the $\mathrm{Li}^{+}, \mathrm{Na}^{+}, \mathrm{K}^{+}$, $\mathrm{Mg}^{2+}$, or $\mathrm{Ca}^{2+}$ form, the cation-exchange resin was packed into a cylindrical glass column of $1.5 \mathrm{~cm}$ inner diameter to give a bed height of $c a .25 \mathrm{~cm}$. The bed height was precisely measured for each experiment. The air stream from a SU13 hair-dryer (Tescom Tokyo, Tokyo, Japan) connected to a desk-size programmable thermo-regulator (TXN-600, As One, Osaka, Japan) was used to maintain a column temperature of $30^{\circ} \mathrm{C}$. The eluents used were distilled water or an ethanol-water mixture, the ethanol content of which was in the range of 10 to $40 \%(\mathrm{v} / \mathrm{v})$. For the eluent of any ethanol content, the resin pre-equilibrated with the eluent was packed to give a bed height of $c a .25 \mathrm{~cm}$. Solute solution, $0.5 \mathrm{~mL}$ of $1.0 \%(\mathrm{w} / \mathrm{v})$, was applied to the bed, and was then eluted with eluent supplied by an MP-3N peristaltic pump (Tokyo Rikakikai, Tokyo, Japan) at a flow rate of 1.5 to $3.5 \mathrm{~mL} / \mathrm{min}$. When the eluent was water or $10 \%(\mathrm{v} / \mathrm{v})$ ethanol, the elution profile of the solute was monitored with a YRD-883 refractometer (Shimamuratech, Tokyo, Japan) and recorded with a GL-220 data logger (Graphtech, Kanagawa, Japan). For eluent compositions of 20 to $40 \%$ (v/v) ethanol, the effluent from the column was fractionated at regular time intervals of 80 and $40 \mathrm{~s}$ for the flow rates of 1.5 and $2.7 \mathrm{~mL} /$ min, respectively. When dextran T-110 was used as the solute to estimate the bed voidage, the intervals for fractionation were 40 and $20 \mathrm{~s}$ for the flow rates. The liquid in the fractions was evaporated at $70^{\circ} \mathrm{C}$ in a DN400 oven (Yamato Scientific, Saitama, Japan) under reduced pressure with an A-1000S aspirator (Tokyo Rikakikai, Tokyo, Japan). The dried solute was dissolved in $0.1 \mathrm{~mL}$ water, and the solute concentration was determined using an HPLC system consisting of an LC-10ADVP pump, an RID-10A refractometer and a C-R6A chromatogram recorder (Shimadzu, Kyoto, Japan).

The apparent distribution of the solute, $K_{\text {app }}$, was determined by a moment analysis of the elution curve (Adachi and Matsuno, 1997; Hashimoto, 2005). The normalized first-order statistical moment, $\mu_{1}{ }^{\prime}$, is defined by Eq. (2a) and is related to $K_{\text {app }}$ by Eq. (2b).

$$
\begin{array}{rlr}
\mu_{1}{ }^{\prime} & =\int_{0}^{\infty} t C d t / \int_{0}^{\infty} C d t & \cdots \cdot \text { Eq. } 2 \mathrm{a} \\
& =\left(Z / u_{0}\right)\left[\varepsilon_{\mathrm{b}}+\left(1-\varepsilon_{\mathrm{b}}\right) K_{\text {app }}\right] & \cdots \cdot \text { Eq. } 2 \mathrm{~b}
\end{array}
$$

where $C$ is the solute concentration, $t$ is the time, $u_{0}$ is the superficial velocity, $Z$ is the bed height, and $\varepsilon_{\mathrm{b}}$ is the bed voidage. Because of its large molecular size, the $K_{\text {app }}$ of dextran T-110 is zero. Therefore, it was used for determination of the bed voidage. The $K_{\text {app }}$ values of galactose, tagatose and talose were determined 
Table 1. Properties of resin in various ion forms*

\begin{tabular}{|c|c|c|c|c|c|c|}
\hline DVB [\%] & & 6 & & & 8 & \\
\hline Ion form & $\begin{array}{c}\text { Relative } \\
\text { bed height }^{* *}\end{array}$ & $\begin{array}{l}\text { Density } \\
{[\mathrm{g} / \mathrm{mL}]}\end{array}$ & Porosity & $\begin{array}{c}\text { Relative } \\
\text { bed height }^{* *}\end{array}$ & $\begin{array}{l}\text { Density } \\
{[\mathrm{g} / \mathrm{mL}]}\end{array}$ & Porosity \\
\hline $\mathrm{H}^{+}$ & & 1.135 & 0.726 & & 1.19 & 0.693 \\
\hline $\mathrm{Li}^{+}$ & 0.988 & 1.203 & 0.741 & 0.988 & 1.219 & 0.668 \\
\hline $\mathrm{Na}^{+}$ & 0.908 & 1.206 & 0.675 & 0.919 & 1.269 & 0.644 \\
\hline $\mathrm{K}^{+}$ & 0.856 & 1.231 & 0.661 & 0.869 & 1.389 & 0.574 \\
\hline $\mathrm{Mg}^{2+}$ & 0.864 & 1.223 & 0.689 & 0.907 & 1.251 & 0.653 \\
\hline $\mathrm{Ca}^{2+}$ & 0.800 & 1.226 & 0.656 & 0.861 & 1.303 & 0.629 \\
\hline
\end{tabular}

* Eluent used was water.

** The ratio in bed height of the resin in any ion-form to that in the hydrogen-ion form.

Table 2. Apparent distribution coefficients of galactose, tagatose and talose to the resin in various ion forms*

\begin{tabular}{ccccccccc}
\hline DVB [\%] & \multicolumn{3}{c}{6} & \multicolumn{3}{c}{8} \\
Ion form & $\varepsilon_{\mathrm{b}}^{* *}$ & Galactose & Tagatose & Talose & $\varepsilon_{\mathrm{b}}^{* *}$ & Galactose & Tagatose & Talose \\
\hline $\mathrm{Li}^{+}$ & 0.395 & 0.320 & 0.301 & 0.441 & 0.387 & 0.206 & 0.173 & 0.293 \\
$\mathrm{Na}^{+}$ & 0.398 & 0.427 & 0.356 & 0.641 & 0.378 & 0.333 & 0.257 & 0.560 \\
$\mathrm{~K}^{+}$ & 0.382 & 0.514 & 0.395 & 0.711 & 0.395 & 0.415 & 0.299 & 0.639 \\
$\mathrm{Mg}^{2+}$ & 0.385 & 0.294 & 0.252 & 0.364 & 0.379 & 0.181 & 0.162 & 0.255 \\
$\mathrm{Ca}^{2+}$ & 0.402 & 0.418 & 0.791 & 1.765 & 0.390 & 0.307 & 0.662 & 1.633 \\
\hline
\end{tabular}

* Eluent use was water.

** Voidage of the bed packed with each resin.

from the plots of the $\mu_{1}{ }^{\prime}$ values against the $Z / u_{0}$ values.

\section{Results and Discussion}

Effects of counter-ion form on the resin properties Table 1 lists the densities and porosities of the resins in various ion-forms. For the resins in the same ion-form, the resin with the $8 \%$ DVB content had higher density and smaller porosity than that with $6 \%$ DVB content. The trend was that the larger ion showed higher density and smaller porosity.

Distribution coefficients on cation-exchange resins of various ion forms The $K_{\text {app }}$ values of galactose, tagatose and talose onto the resins in various ion-forms are listed in Table 2 as well as the bed voidage $\varepsilon_{\mathrm{b}}$. The eluent used was water. The $K_{\text {app }}$ values of tagatose and talose were larger for the resins with both $6 \%$ and $8 \%$ DVB contents in the order $\mathrm{Mg}^{2+}, \mathrm{Li}^{+}, \mathrm{Na}^{+}, \mathrm{K}^{+}$, and $\mathrm{Ca}^{2+}$, while the values for galactose were in the order $\mathrm{Mg}^{2+}<\mathrm{Li}^{+}<\mathrm{Ca}^{2+}, \mathrm{Na}^{+}$and $\mathrm{K}^{+}$for the resins with $6 \%$ and $8 \%$ DVB contents. The differences in the $K_{\text {app }}$ values among the three solutes were the largest for the resin in the $\mathrm{Ca}^{2+}$ form, and next largest for the resin in the $\mathrm{K}^{+}$form. The $K_{\text {app }}$ values, or the difference in the $K_{\text {app }}$ values, reflect the mean residence times of the solutes, that is, they are equilibrium parameters. The practical separation process includes another important parameter related to rate process, that is, the sharpness and symmetry of the chromatograms.

Figures 1(a) and (b) show the elution profiles of the three solutes for the resins in the $\mathrm{K}^{+}$and $\mathrm{Ca}^{2+}$ forms, respectively, with $8 \%$ DVB content. Distilled water was used as the eluent. The
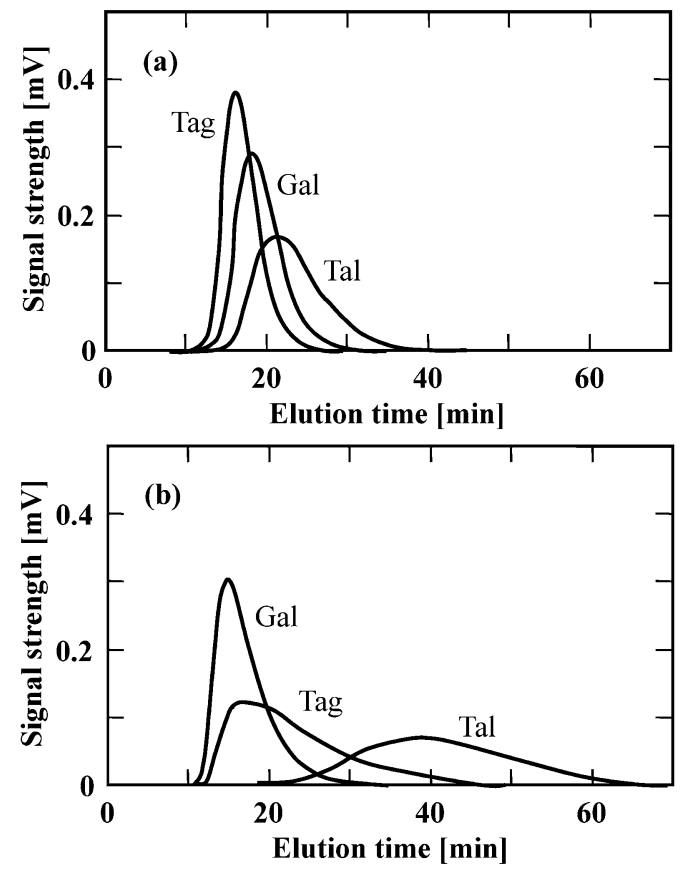

$\mathrm{Ca} 2+$

Fig. 1. Elution profiles of galactose (labeled Gal), tagatose (Tag) and talose (Tal) for the resins in the (a) $\mathrm{K}^{+}$and (b) $\mathrm{Ca}^{2+}$ forms with $8 \%$ DVB content at $30^{\circ} \mathrm{C}$. The eluent used was water.

chromatograms for the resin in the $\mathrm{Ca}^{2+}$ form were broader and more asymmetrical than those for the resins in the $\mathrm{K}^{+}$form. The resin with the higher DVB content did not shrink significantly in comparison to the resin with low DVB content at high solute or alcohol concentration (Adachi and Matsuno, 1997). Therefore, the 


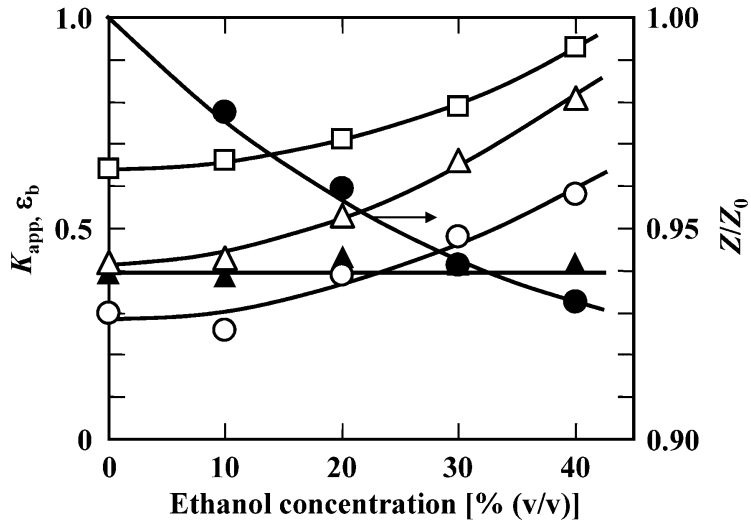

Fig. 2. (○) Relative bed height, $Z / Z_{0},(\boldsymbol{\Delta})$ bed voidage, $\varepsilon_{\mathrm{b}}$, and the $K_{\text {app }}$ values for $(\triangle)$ galactose, $(\bigcirc)$ tagatose and $(\square)$ talose for eluent containing different ethanol content for the resin in the $\mathrm{K}^{+}$form with $8 \%$ DVB content at $30^{\circ} \mathrm{C}$.

resin in the $\mathrm{K}^{+}$form with $8 \%$ DVB content was selected to be the most effective for the separation of the three solutes.

Effects of the ethanol content of the eluent on the distribution coefficients onto the resin of $K^{+}$form The effects of the ethanol content of the eluent on the bed shrinkage and the $K_{\text {app }}$ values of galactose, tagatose, and talose were examined for the resin in the $\mathrm{K}^{+}$form with $8 \% \mathrm{DVB}$ content at $30^{\circ} \mathrm{C}$ (Fig. 2). As the ethanol content of the eluent was increased, the shrinkage of the bed increased. The $K_{\text {app }}$ values for all three solutes increased when the ethanol content of the eluent was increased. On the other hand, as the ethanol content increased, the difference in the $K_{\text {app }}$ values between galactose and tagatose became larger, while the difference in the $K_{\text {app }}$ values between talose and galactose became smaller. The solute with the smaller $K_{\text {app }}$ is eluted at the shorter residence time, and the peak becomes sharper (Hashimoto, 2005). Therefore, when the three solutes are chromatographically separated from the reaction mixture obtained by the treatment of galactose in the subcritical aqueous ethanol, the removal or evaporation of the ethanol from the mixture is recommended prior to the separation. Removal of the ethanol would result in an increase in solute concentrations. Evaluation of the parameters related to the intraand inter-particle diffusion processes of the solutes would be further required in order to reasonably design the separation process.

Acknowledgement The resins used was supplied by by Mitsubishi Chemical Corp., Tokyo, Japan.

\section{References}

Adachi, S. and Matsuno, R. (1997). Effect of eluent composition on the distribution coefficient of saccharides on to a cation-exchange resin in sodium-ion form. Biosci. Biotechnol. Biochem., 61, 1296-1301.

Caruel, H., Rigal, L., and Gaset, A. (1991). Carbohydrate separation by
liganD-exchange liquid chromatography: Correlation between the formation of sugar-cation complexes and the elution order. $J$. Chromatogr. A, 558, 89-104.

Gao, D.M., Kobayashi, T., and Adachi, S. (2015). Production of rare sugars from common sugars in subcritical aqueous ethanol. Food Chem., 175, 465-470

Goulding, R.W. (1975). Liquid chromatography of sugars and related polyhydric alcohols on cation exchangers: $J$. Chromatogr., 103, 229-239.

Granström, T.B., Takata, G., Tokuda, M., and Izumori, K. (2004). Izumoring: A novel and complete strategy for bioproduction of rare sugars. J. Biosci. Bioeng., 97, 89-94.

Hashimoto, K. (2005). In Chromatographic Separation Engineering (in Japanese), Baifukan, Tokyo, pp. 26-27, 64-66.

Hossain, A., Yamaguchi, F., Matsunaga, T., Hirata, Y., Kamitori, K., Dong, Y., Sui, L., Tsukamoto, I., Ueno, M., and Tokuda, M. (2012). Rare sugar D-psicose protects pancreas $\beta$-islets and thus improves insulin resistance in OLETF rats. Biochem. Biophys. Res. Commun., 425, 717-723.

Kim, H.J., Ryu, S.A., Kim, P., and Oh, D.K. (2003). A feasible enzymatic process for D-tagatose production by an immobilized thermostable 1-arabinose isomerase in a packed-bed bioreactor. Biotechnol. Prog., 19, 400-404.

Levin, G.V., Zehner, L.R., Saunders, J.P., and Beadle, J.R. (1995). Sugar substitutes: their energy values, bulk characteristics, and potential health benefits. Am. J. Clin. Nutr., 62, 1161-1168.

Lu, Y., Levin, G.V., and Donner, T.W. (2008). Tagatose, a new antidiabetic and obesity control drug. Diabetes Obes. Metab., 10, 109-134.

Matsuo, T., Suzuki, H., Hashiguchi, M., and Izumori, K. (2002). D-Psicose is a rare sugar that provides no energy to growing rats. J. Nutr. Sci. Vitaminol., 48, 77-80.

Morimoto, K., Park, C.S., Ozaki, M., Takeshita, K., Shimonishi, T., Granström, T.B., Takata, G., Tokuda, M., and Izumori, K. (2006). Large scale production of D-allose from D-psicose using continuous bioreactor and separation system. Enzyme Microb. Technol., 38, 855-859.

Söderling, E. Mäkinen, K.K., Chen, C.-Y., Pape, H.R. Jr., Loesche, W., and Mäkinen, P.-L. (1989). Effect of sorbitol, xylitol, and xylitol/sorbitol chewing gums on dental plaque. Caries Res., 23, 378-384.

Stefansson, M. and Westerlund, D. (1996). Ligand-exchange chromatography of carbohydrates and glycoconjugates. J. Chromatogr. A, 720, 127-136.

Takamine, S., Iida, T., Okuma, K., Shimonishi, T., Izumori, K., and Matsuo, T. (2009). Method for producing sugar composition containing definite amount of target hexose and having sugar composition ratio different from starting sugar material, and use of sugar composition thus produced. Japanese Patent 2009-081976 (WO 2010/113785 A1).

Takeshita, K., Suga, A., Takada, G., and Izumori, K. (2000). Mass production of D-psicose from D-fructose by a continuous bioreactor system using immobilized D-tagatose 3-epimerase. J. Biosci. Bioeng., 90, $453-455$ 